\title{
Hydrology of Arctic rivers
}

\author{
O. T. Gudmestad \\ Department of Mechanical and Structural Engineering and Material \\ Science, University of Stavanger, Norway
}

\begin{abstract}
Several of the rivers in the Arctic possess distinct features as many of them are running northwards complicating the flow during the ice break up season. This causes severe flooding of large areas and damages to the built environment. Strategies to ensure the flow of the ice to avoid flooding of huge areas due to ice dams are discussed.

The global warming increases the challenges related to the hydrology of the Arctic rivers as the warming temperature will lead to increased erosion of the riverbank with increased transport of mud, accumulation of materials on the riverbed and near the river outlet with associated problems to navigate the rivers, in particular near the sea. This will call for increased dredging to keep the rivers navigable.

The increased erosion caused by the melting of permafrost also makes river crossings more challenging as supports for bridges and pipeline crossings are being undermined by the melting riverbanks. Technical solutions are discussed.

Finally, a discussion of how the use of the rivers during the winter will be threatened by a warming climate is included, as the length of the ice season when ice roads can be used will be reduced.

Keywords: river ice, ice breakup, erosion, sediment transport, flooding.
\end{abstract}

\section{Introduction}

The hydrology of rivers in cold regions is governed by the cold climate, the ice on the surface, the ice break up and the presence of permafrost that melts along the riverbanks during the summer with transport of sediments.

During wintertime, the ground is continually frozen from the surface down to the permafrost and rivers as well as fresh water lakes are covered by ice, which at some locations can be several meters thick. Shallow fresh water ponds are frozen 
to the bottom, whereby no water is accessible from these ponds for the communities. The frozen rivers and lakes are used to transport goods to cold climate areas (on ice roads), to transport raw materials and for preparation of construction works. For calculation of the bearing capacity of the ice, see ISO [1].

During the summer season, which may start from mid to late June and continue to mid to late August, the upper layer of the permafrost melts, resulting in the ground becoming non accessible by vehicles, and pollution might easily be carried with the water flow.

Water into rivers is also coming from the melting of glaciers, which is dependent upon the temperature, and the sum of the product of the average hourly temperature multiplied by the number of hours with this temperature will determine the melting rate. A tendency of increased flooding will be seen with an increase of the "melting degrees hours". On the other hand, whether the glaciers will be growing or shrinking will depend upon the net mass flux: snowfall minus melting. Where the glaciers are shrinking, there is a danger of imbalance in the future hydrology budget.

In between the summer and winter, there is the freeze-up period and the snowmelt period. In the freeze-up period, the ground freezes gradually and all ponds freeze. At some locations (such as Barrow, Alaska), precipitation is considerable during this period of the year, with a soaked surface layer as the freezing continues into deeper layers until the upper layers above the permafrost are entirely frozen. During rainfall, the ground becomes almost non-navigable and there is a considerable surface water flow with swelling rivers.

During the snowmelt period, the runoff is considerable at the surface, but the flow does not penetrate deeply, as the lower layers are still frozen. Considerable flow can occur during this season, depending upon the temperature and the speed of the melting. Water can find new access ways and can cause considerable local damage. Vegetation will insulate the ground layers and be a binding material so the flow will find a route outside of vegetation. Any damage due to the use of heavy equipment can lead to increased surface damage during this period.

The rivers in cold climate areas (and there are huge rivers running north to the Arctic seas, ACIA [2]) are exposed to enormous changes in the water level from the dry winter, where the surface freezes, and there is limited water transport to the huge amount of water that will be transported in the snow melt season. In this period, the ice break up also represents challenges, as the ice may pile up and jam the flow. Huge areas can be flooded and the broken ice can substantially damage landscape, vegetation and engineered structures. Furthermore, the rapid flow of water in this period also causes riverbanks erosion, extensive sediment transport and scouring around bridge supports, which can cause bridge collapse.

In the following, the specific challenges to the public caused by the river hydraulic regime will be studied. The challenges and present conceptual solutions will be described, and in some cases, the solutions implemented by communities located in cold climate regions will be referred. The challenges discussed relate to:

- River flow during the snow melting season

- The specifics during the river ice break up 
- $\quad$ Sediment transport

- $\quad$ Spreading of pollution

- Sewage transport

The objective of the presentation is thus to make a wider audience aware of the specifics and the challenges of managing the hydrology of the Arctic rivers.

\section{River flow during the snow-melting season}

\subsection{Description}

The flow of water in Arctic rivers has a seasonal character, see Figure 1, with a low flow during the dry and cold winter where the river freezes, a very high flow during the snow melt season and a gradual decrease in the flow during the summer, in particular in areas with little summer precipitation. The flow increases again before the freeze up period when some rainfall is normal. Figure 1 shows the variation in the water flow in the Mackenzie River, one of the large Arctic rivers. Some of the largest rivers in the world discharge into the Arctic seas. The major Arctic rivers are as listed in Table 1.

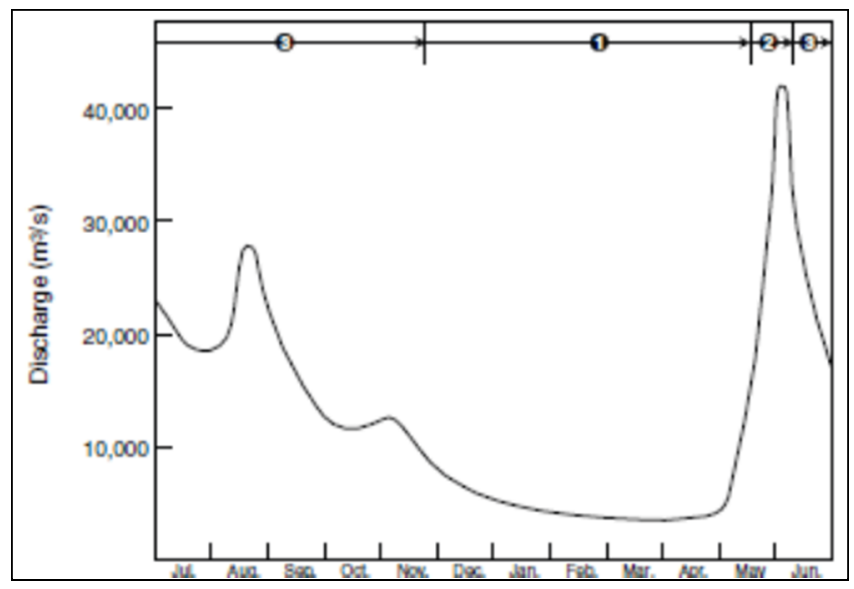

Figure 1: Typical seasonal variation of the flow of water in the Mackenzie River, Arctic Council (Owens et al. [3]).

\section{The engineering challenges}

The large variation in the flow provides a number of challenges. The primary challenge is the erosion of the riverbank; the damage caused by the flowing ice and the flooding; see also Section 3. The erosion causes the riverbanks to become unstable and engineered structures can be undermined. This applies in particular to bridges spanning the river and to river port facilities. Erosion is also a large challenge for pipeline crossings. Flooding causes damage to all engineered structures in large areas along the river. 
Table 1: Rivers discharging into Arctic seas (Bachman [4]).

\begin{tabular}{|c|c|c|}
\hline River & Country & $\begin{array}{c}\text { Discharge in cubic } \\
\text { kilometers per year }\end{array}$ \\
\hline Dvina & Russia & 105 \\
\hline Pechora & Russia & 108 \\
\hline Ob & Russia & 402 \\
\hline Yenisei & Russia & 580 \\
\hline Lena & Russia & 525 \\
\hline Kolyma & Russia & 103 \\
\hline Yukon & US (Alaska) & 203 \\
\hline Mackenzie & Canada & 281 \\
\hline
\end{tabular}

\subsection{Mitigation measures to avoid damage in strong river flow}

In order to mitigate the effects of the flooding due to snowmelt, several measures must be taken to protect engineered structures:

- Like any harbor, breakwaters and rock or concrete block plastering can protect the banks. It is important to calculate the dimensions of the plastering to ensure that it can stand up to the current flow, see Tørum et al. [5]. In addition, the plastering or breakwaters must withstand the actions from the drifting ice during the ice break up, see Tørum [6]. Recently, the use of textiles (Figure 2) has been suggested for plastering, see Caline [7]; however, the textile must be sufficiently robust to withstand the actions to which they are exposed. Annual replacement of lost bags is required. It is expected that more work will be conducted in the future to develop suitable materials.

- With a trend of Arctic warming, there will be increased permafrost melting and the speed of erosion could accelerate. In addition, erosion destroys the vegetation, so erosion is self-reinforcing as vegetation holds the soil in place. It should also be noted that extensive erosion would cause large sediment transport with accumulation of sand or mud banks in the rivers, potentially in the river estuaries, hindering access by vessels. In addition, dredging might be necessary to avoid flooding upstream.

- Bridges must be supported in a manner that the riverbank and mid-river supports are not exposed to erosion. A layer of scour protection around the supports might achieve this. The scour protection would often consist of rock of a sufficient size to avoid being transported with the river current, see Hughes [8].

- Furthermore, the bridge supports must be designed to withstand the actions from ice. Of special interest is the bridge piers designed for the St Lawrence River crossing to Prince Edwards Island, the Confederation Bridge (see Figure $3)$. The piers have coned geometry in the waterline so ice can break up when forced against the bridge piers (Løset et al. [9], Frederking et al. [10]).

- Of particular concern is, furthermore, the height of the bridge deck. In cases where the water flows against the bridge deck, there is a large possibility for loss of the bridge. This calls for data collection of the current speed, maximum 
water level and ice conditions. Traditional knowledge regarding past extremes should be consulted to help define the extreme design situation. Like offshore structures for oil and gas, a safety level should be selected to ensure that the probabilities of bridge damage and bridge collapse are within acceptable levels agreed by the society. For offshore structures for the oil and gas industry, these levels are set as annual exceedances of $10^{-2}$ and $10^{-4}$, respectively, see ISO [1].

- Pipelines for oil and gas produced from onshore fields will often have to cross rivers. They might cross rivers on bridges that should be designed according to the principles defined above, or they might cross rivers on the river bottom. In the last case, the pipelines will be exposed to strong transverse currents and must be designed to be stable on the bottom. Trenching might be required, although scouring might undermine the pipeline and cause free span. Erosion of the riverbank might be even more dangerous and cause free spanning pipelines exposed to considerable currents, possibly causing pipeline breakage. Utmost care must, therefore, be taken to design pipeline river crossings to avoid large pollution effects.

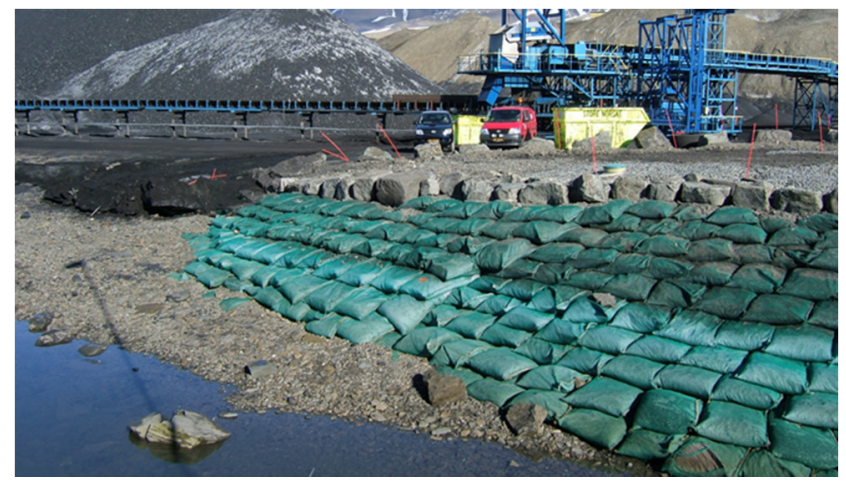

Figure 2: Testing the use of geobags to reduce erosion at Svea mine, Spitzbergen (Caline [7]).

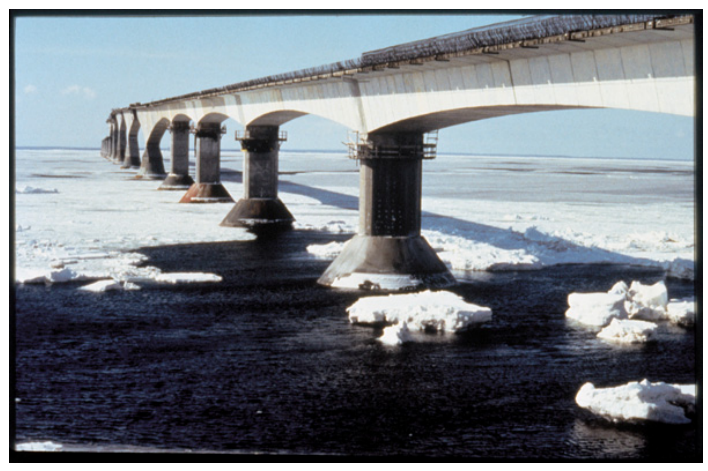

Figure 3: Confederation Bridge (Canada) while under construction (Bercha Group [11]). 


\section{Public challenge: the specific conditions during the ice break up}

During the ice break up in the spring, there are challenges associated with large loading on riverbanks, structures placed in the rivers and there is potential for flooding of large areas.

\subsection{The conditions caused by the ice break up}

Many of the rivers in the Arctic region flow towards the north and ice begins to melt in the south while the river is still frozen in the north. This situation creates flooding that may be excessive in the south and creates huge water and ice pressure on the ice in the north, potentially causing the ice to pile up and jam the river flow, causing even larger flooding.

A series of images demonstrating this phenomenon is shown in Figure 4. The images are taken by the Moderate Resolution Imaging Spectra-radiometer (MODIS) on NASA's Terra satellite, showing the spring flooding in May 2007.

The images were made with both infrared and visible light. Land, burned by wildfire in the past year or two, is red-brown. The first image was taken on May 14, 2007, while the river was still frozen, (NASA [12]).

The second image was taken on May 23. The southern extents of the Lena and its surrounding areas are dramatically flooded.

The last image was taken a week later on May 28 and the floods had moved north. Water had, however, spread far beyond the river's banks. The flood put 12 towns (1,000 houses) under water, damaged or destroyed 41 bridges, and affected more than 14,000 people, (NASA [12]).

Figure 5 shows the flooding situation in Yakutsk on May 20, 2010.

\subsection{Mitigating measures to avoid large damages}

Even if it may not be possible to avoid flooding caused by snow melt and ice break up, it is of importance to provide forecasts such that people living in the area where flooding might be expected can take necessary precautions. Evacuation should be properly planned (each household should have a boat available for evacuation) and the most important buildings should be located on higher grounds. In order to plan properly, historical knowledge of the extent of flooding must be consulted in order to provide a suitable design basis for all planning works.

Ice jamming downstream might worsen the flooding situation considerably. Potentially, the use of explosives will help to open the jammed section. Ice jam at a river crossing might damage the bridge and cause large losses, both in terms of money and in terms of the time it will take to rebuild the bridge. Figure 6 shows how the Kuskokwim River threatens to flood the Western Alaska village of lower Kalskag on May $7^{\text {th }} 2012$. 


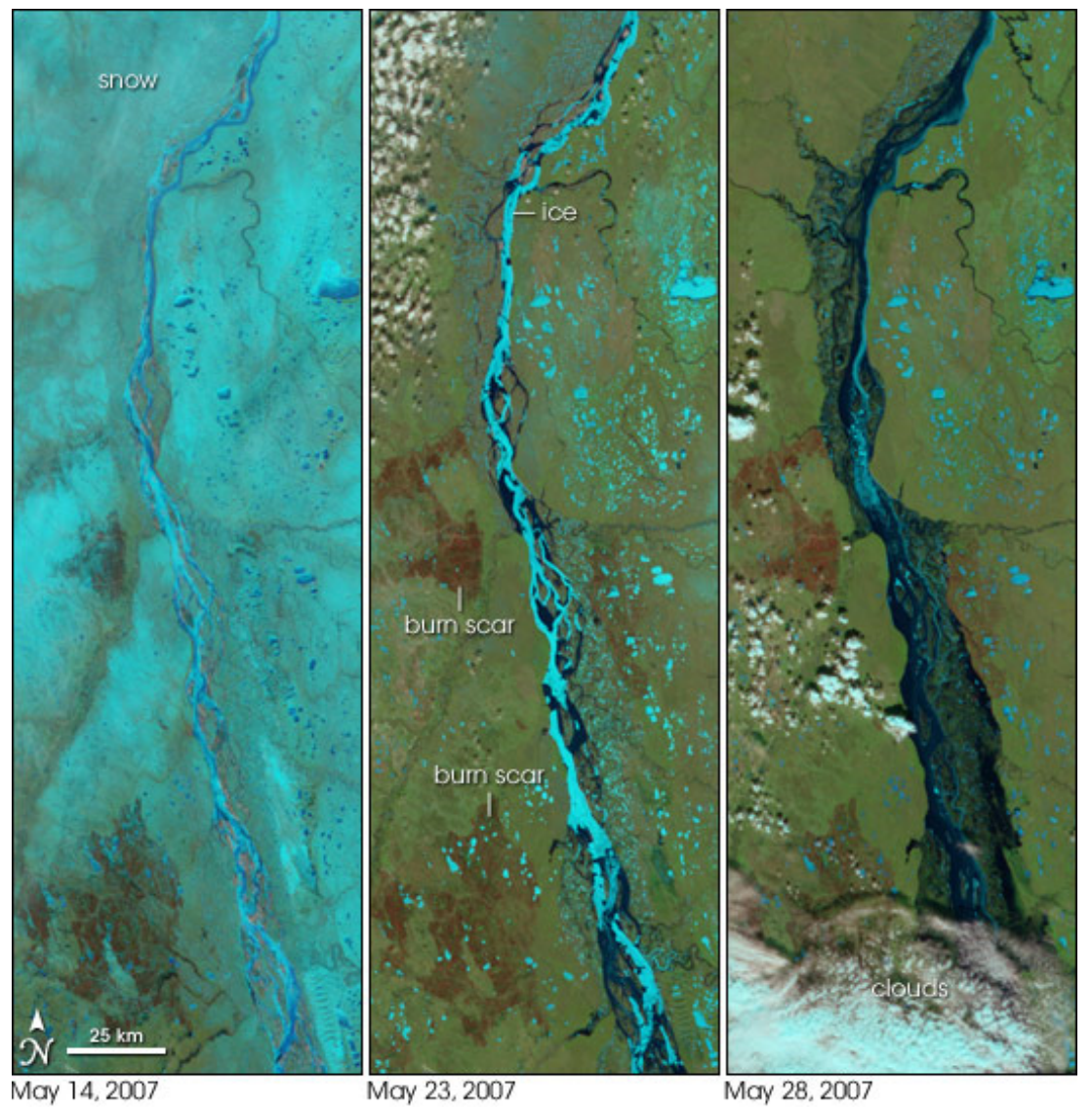

Figure 4: The ice break up on river Lena, Siberia, 2007 (NASA [12]).

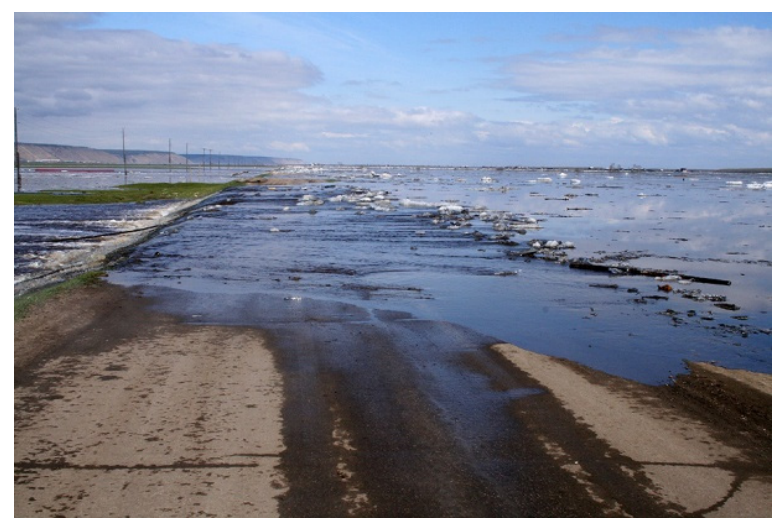

Figure 5: $\quad$ Spring flood in Yakutsk. This picture was taken on May 20, 2010, [13]. Ref. photographer Bolot Bochkarev. 


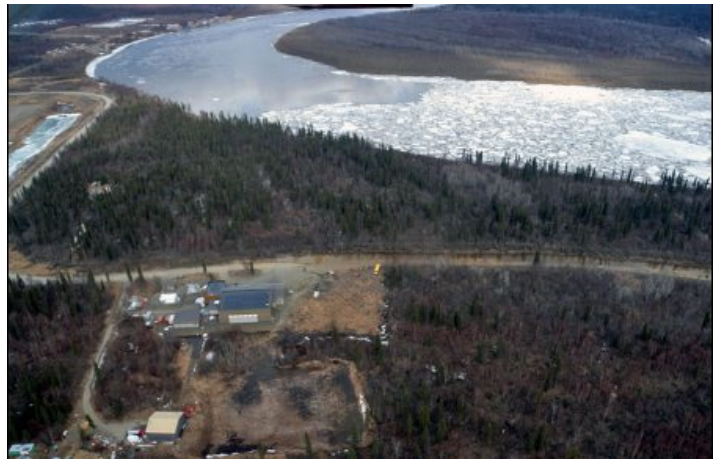

Figure 6: Kuskokwim River is threatening to flood an Alaskan village. Picture is from the Alaska Division of Homeland Security's river watch (DeMarban [14]).

\section{Summary and conclusions}

With reference to Kane [15], the schematic of the arctic hydrological cycle in a region of thick ice-rich permafrost where groundwater interactions is not a consideration can be presented as in Figure 7. Snowmelt is the most important event leading to large water flow and considerable challenges to engineered structures. In the event it is not responded properly to these challenges, large damage may occur. In this paper, descriptions of the challenges have been provided and it has been pointed to solutions that may be implemented to minimize the damage. Of particular recommendation are measures to avoid environmental damages and consultation with the local society to identify past events that could be dimensioning for future events. This will however, not lead us to disregard models considering new trends, such as planning for a potentially future warmer climate.

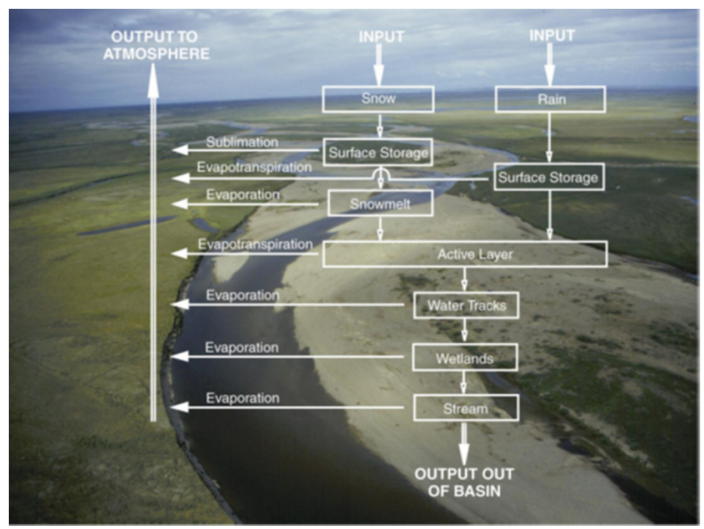

Figure 7: Schematic of the arctic hydrological cycle in a region of thick ice-rich permafrost where groundwater interactions are not a consideration, see Ming-Kong et al. [16]. 


\section{References}

[1] International Standardization Organization, ISO 19906, 2010, Arctic Offshore Structures, ISO, Geneva, Dec.

[2] ACIA Map of Arctic River Basins. http://www.arctic.noaa.gov/detect/landriver-acia-image.shtml

[3] Owens, E., Solsberg, L. B., West, M. R. and McGrath, M., 1988, Field guide for oil spill response in Arctic waters, prepared for Arctic Council Emergency, Prevention, Preparedness and Response (EPPR) Working Group. Environment Canada, Yellowknife, NT Canada, 348 pages. See also: www.fargisinfo.com/Referanser/LinkedDocuments/fldguide.pdf

[4] Bachman, J., 2010, Special Report: Oil and ice: worse than the Gulf spill? http://www.reuters.com/article/2010/11/08/us-russia-oilidUSTRE6A71IL20101108

[5] Tørum, A., Burcharth, H.F., Goda, Y., Kortenhaus, A. and Kriebel, D., 2007, A new International Standard for Actions from Waves and Currents on Coastal Structures. JM Smith (ed.), in: Coastal Engineering Proceedings of the 30th International Conference: San Diego, California, USA September 3 to 8, 2006. Vol. 5, World Scientific, pp. 4290-4302.

[6] Tørum, A., 2012, Coastal Structures: Action from Waves and Ice. In: Kim, Y. C. (ed.), Series on Coastal and Ocean Engineering Practice, Vol. 1, World Scientific. http://www.berchagroup.com/

[7] Caline, F., 2010, Coastal sea ice action on a breakwater in a microtidal inlet in Svalbard, PhD Thesis NTNU, Trondheim, No. 226, October.

[8] Hughes, S. A., 2001, Scour and scour protection, US Army Corps of Engineers, Trinidad, 24-28 September. http://www.oas.org/cdcm_train/ courses/course4/chap_8.pdf

[9] Løset, S., Shkhinek, K., Gudmestad, O. and Høyland, K., 2010, Impact of ice on offshore and onshore facilities, LAN Publishing House, St. Petersburg.

[10] Frederking, R., Kubat, I. and S. Prinsenberg, S., 2006, Response of two piers on Confederation Bridge to ice loading event of April 4, 2003, Proceedings of 18th International Symposium on Ice, IAHR'06, Vol. 1, pp. 231-238, Sapporo, Japan.

[11] Bercha Group, Homepage of Bercha Group, Consulting Services Since 1975, http://www.berchagroup.com/

[12] NASA Earth Observatory. Flooding on the Lena River. http://earthobservatory.nasa.gov/NaturalHazards/view.php?id=18428

[13] Yakutsk, May 20, 2010 Spring Flood: the Lena River, Yakutsk, Yakutia/ Siberia. http://www.flickr.com/photos/bolotbootur/http://nca2009.global change.gov/alaskasets/72157624105010964/

[14] DeMarban, A., 2012, Spring river flooding threat wanes across Alaska, save a few iffy villages. Alaska Dispatch http://www.alaskadispatch.com/article/ spring-river-flooding-threat-wanes-across-alaska-save-few-iffy-villages

[15] Kane, D. 1., 2000, Arctic Hydrological Processes. In: Hinzman, L. and Vörösmarty, C.; NSF-ARCSS Workshop on Arctic System hydrology, St 
Barbara, September. http://arcticchamp.sr.unh.edu/pdffiles/ hinzmanvorosmarty2001.pdf

[16] Woo Ming-Kong et al., 2007, Science Meets Traditional Knowledge: Water and Climate in the Sahtu (Great Bear Lake) Region, Northwest Territories, Canada, Arctic, 60(1), pp. 37-46. http://pubs.aina.ucalgary.ca/ arctic/Arctic60-1-37.pdf 